\title{
Thermodynamic Functions of Terbium Hafnate
}

\author{
A. V. Guskov ${ }^{a, *}$, P. G. Gagarin ${ }^{a}$, V. N. Guskov ${ }^{a}$, A. V. Tyurin ${ }^{a}$, A. V. Khoroshilov ${ }^{a}$, and K. S. Gavrichev ${ }^{a}$ \\ ${ }^{a}$ Kurnakov Institute of General and Inorganic Chemistry, Russian Academy of Sciences, Moscow, 119991 Russia \\ *e-mail:a.gus@igic.ras.ru
}

Received January 26, 2021; revised January 27, 2021; accepted January 27, 2021

\begin{abstract}
The molar heat capacity of terbium hafnate with a pyrochlore structure was measured by relaxation and adiabatic calorimetry. The smoothed values of the molar heat capacity were used to calculate the thermodynamic functions in the temperature range 6-330 K. The general form of the Schottky anomaly was determined.
\end{abstract}

Keywords: terbium hafnate, thermodynamic functions, Schottky anomaly

DOI: $10.1134 / \mathrm{S} 0036023621060103$

\section{INTRODUCTION}

Terbium hafnate belongs to the class of high-temperature binary oxides $\mathrm{Ln}_{2} \mathrm{Hf}_{2} \mathrm{O}_{7}(\mathrm{Ln}=\mathrm{La}-\mathrm{Tb})$ with a pyrochlore structure $(\mathrm{Fd} 3 \mathrm{~m})$. Terbium hafnate crystallizes in the region of continuous series of solid solutions $(1-x) \mathrm{TbO}_{1.5} \cdot x \mathrm{HfO}_{2}(x \approx 0.45-1.0)$ with a disordered fluorite structure $(F m 3 m)$ based on cubic hafnium dioxide. $\mathrm{Tb}_{2} \mathrm{Hf}_{2} \mathrm{O}_{7}$ undergoes no structural transformations until a temperature of $\sim 2500 \mathrm{~K}$, at which it transforms to a disordered fluorite structure [1-3]. As other pyrochlore-structure binary oxides of lanthanides and group $4 \mathrm{~b}$ metals, terbium hafnate shows great promise as ionic conductors, semiconductors, scintillators, nuclear industry materials, and also substances for design thermal barrier coatings (TBCs) and environmental barrier coatings (EBCs) $[4,5]$. Shlyakhtina et al. studied the structural and electrical properties of terbium hafnate [6]. Aung et al. synthesized highly transparent optical ceramics [7], and Yasuhara and Ikesue investigated their magnetooptical properties [8]. Special attention has been given to the formation of nanocrystalline terbium hafnate and its conversion to normal-size crystalline ceramics of the pyrochlore structural type [5,9-11]. The most interesting study of the set of the physical properties of $\mathrm{Tb}_{2} \mathrm{Hf}_{2} \mathrm{O}_{7}$ pyrochlore in the range $1.8-300 \mathrm{~K}$ was made by Anand et al. [12], who explored the magnetic properties, measured the molar heat capacity, and analyzed the increment in the molar heat capacity due to the interaction of the crystal field and $4 f$ electrons of terbium hafnate (Schottky anomaly). Unfortunately, the temperature dependence of the molar heat capacity and the Schottky anomaly were presented in that work [12] only in graphical form and cannot be used for calculations, whereas the molar heat capacity and the thermodynamic functions calculated from it are highly important characteristics of a substance. The purpose of this work was to measure the molar heat capacity in the temperature range to $330 \mathrm{~K}$ and calculate the thermodynamic functions: entropy, enthalpy, and reduced Gibbs energy.

\section{EXPERIMENTAL}

Terbium hafnate was synthesized by reverse precipitation. The initial substances were terbium sesquioxide (99.99 wt \%, LLC Lankhit), hafnium dioxide (99.99 wt \%, LLC Lankhit), hydrochloric acid (35-38 wt $\%$, special-purity grade $20-4$, LLC Khimmed), and ammonia solution (25-28 wt \% $\mathrm{NH}_{4} \mathrm{OH}$, specialpurity grade, LLC Khimmed). The methods of synthesis, measurement of thermal expansion and heat capacity, and processing of results were described in detail previously $[13,14]$. The final annealing at $1550 \mathrm{~K}$ for $4 \mathrm{~h}$ gave $\mathrm{Tb}_{1.994} \mathrm{Hf}_{2.006} \mathrm{O}_{7.003}$. Such a deviation from stoichiometry cannot introduce a significant error to the molar heat capacity [15]. X-ray powder diffraction studies showed that the obtained single-phase sample has a cubic structure of the pyrochlore type with the unit cell parameter $a=10.455(4) \AA$ (Fig. 1), which agrees satisfactorily with the literature data $[12,16]$. Scanning electron microscopy demonstrated (Fig. 2) that the sample is not nanosized; therefore, there is no need in making corrections for the size factor. The molecular weight was calculated from the atomic weights [17] and was $786.8265 \mathrm{~g} / \mathrm{mol}$. The molar heat capacity was measured by relaxation calorimetry with a Quantum Design PPMS-9 automated physical property measurement system and by adiabatic calorimetry with a BKT-3 automatic low-temperature calorimeter (LLC Termis). 


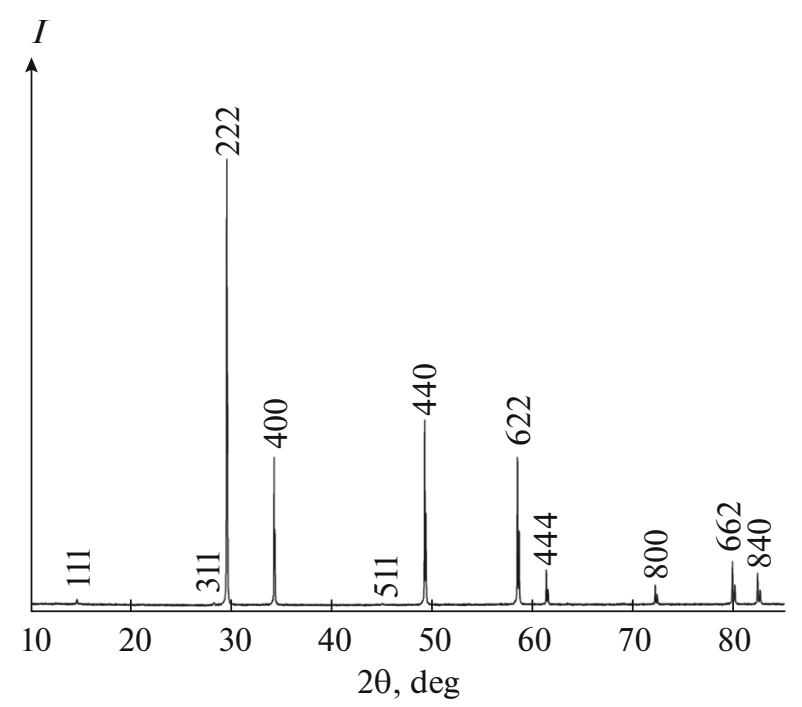

Fig. 1. X-ray powder diffraction pattern of $\mathrm{Tb}_{2} \mathrm{Hf}_{2} \mathrm{O}_{7}$ of the $F d 3 m$ (pyrochlore) structural type with $a=10.455(4) \AA$.

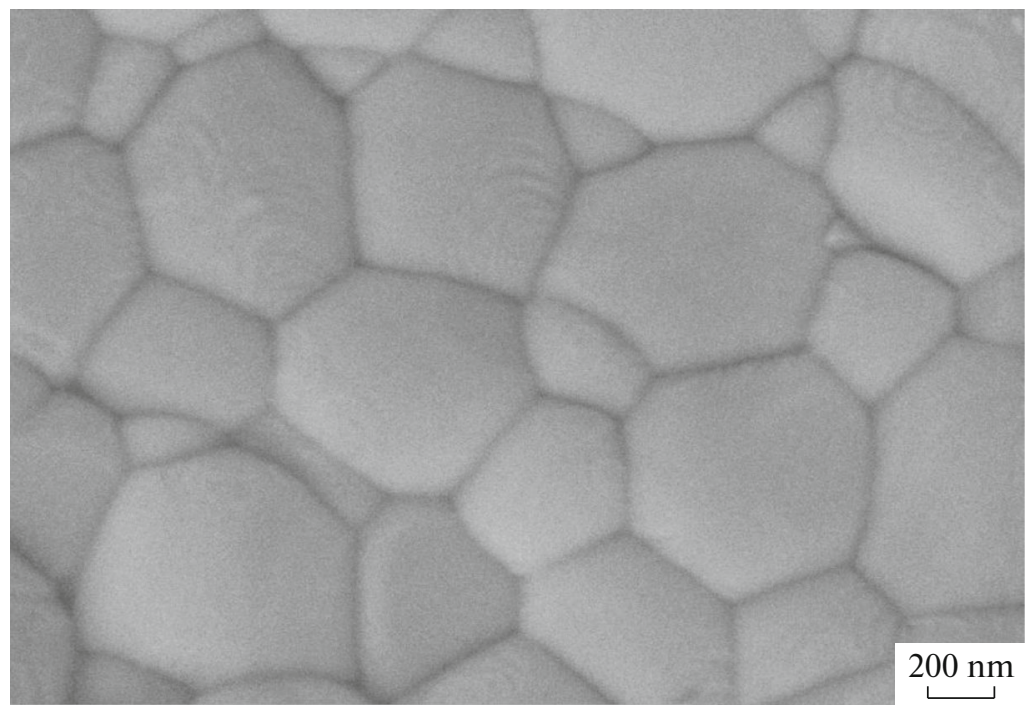

Fig. 2. Morphology of the surface of a sample of terbium hafnate (pyrochlore).

\section{RESULTS AND DISCUSSION}

The molar heat capacity of terbium hafnate with a pyrochlore structure was measured by relaxation (5.8$43.9 \mathrm{~K})$ and adiabatic $(6.0-327.1 \mathrm{~K})$ calorimetry in 38 and 120 temperature points, respectively (Table 1).

The experimental values of the molar heat capacity were smoothed using the following equations [18]:

$$
\begin{gathered}
C_{p}=\Sigma a_{i} \ln (T / 400)^{i}(6-15 \mathrm{~K}) \\
C_{p}=3 R \Sigma a_{i}\left(\left(\theta_{i} / T\right)^{2}\right) e^{\theta i / T} /\left(e^{\theta i / T}-1\right)^{2}(15-330 \mathrm{~K})(2)
\end{gathered}
$$

Table 2 presents the coefficients of Eqs. (1) and (2).

The dependence of the molar heat capacity in the range $6-330 \mathrm{~K}$ is smooth and contains no structural anomalies. The most interesting region is the lowtemperature range (6-25 K, Fig. 3). Here, as in Anand et al. [12], the curve of the molar heat capacity has a minimum $\left(\sim 2 \mathrm{~J} \mathrm{~mol}^{-1} \mathrm{~K}^{-1}\right)$ at $\sim 8 \mathrm{~K}$. A further decrease in temperature leads to an increase in the molar heat capacity due to the increasing branch of a magnetic transformation, which occurs at a temperature $<2 \mathrm{~K}$. This phenomenon is particularly noticeable in comparison with the molar heat capacity of lanthanum hafnate (Fig. 3, curve 4) [19], which has the same structure $F d 3 m$. The magnetic transformation in the range $0-2 \mathrm{~K}$ is characteristic of all the compounds of lanthanides, except lanthanum and lutecium [20]. At temperatures of $0-6 \mathrm{~K}$, the molar heat capacity is mainly determined by the magnetic component 
Table 1. Experimental dependence of the molar heat capacity of terbium hafnate (pyrochlore) on temperature at $p=101.3 \mathrm{kPa}$

\begin{tabular}{|c|c|c|c|c|c|}
\hline$T, \mathrm{~K}$ & $C_{p}, \mathrm{~J} \mathrm{~mol}^{-1} \mathrm{~K}^{-1}$ & $T, \mathrm{~K}$ & $C_{p}, \mathrm{~J} \mathrm{~mol}^{-1} \mathrm{~K}^{-1}$ & $T, \mathrm{~K}$ & $C_{p}, \mathrm{~J} \mathrm{~mol}^{-1} \mathrm{~K}^{-1}$ \\
\hline \multicolumn{6}{|c|}{ Relaxation calorimetry } \\
\hline 5.753 & 2.368 & 11.66 & 3.336 & 23.89 & 12.54 \\
\hline 6.072 & 2.320 & 12.37 & 3.578 & 25.19 & 14.05 \\
\hline 6.413 & 2.290 & 13.02 & 3.875 & 26.61 & 15.70 \\
\hline 6.758 & 2.265 & 13.76 & 4.259 & 28.19 & 17.45 \\
\hline 7.133 & 2.268 & 14.53 & 4.714 & 29.76 & 19.47 \\
\hline 7.523 & 2.273 & 15.35 & 5.239 & 31.45 & 21.50 \\
\hline 7.950 & 2.318 & 16.21 & 5.803 & 33.23 & 23.76 \\
\hline 8.397 & 2.361 & 17.14 & 6.475 & 35.12 & 26.16 \\
\hline 8.868 & 2.438 & 18.11 & 7.230 & 37.12 & 28.81 \\
\hline 9.368 & 2.547 & 19.17 & 8.113 & 39.22 & 31.76 \\
\hline 9.894 & 2.690 & 20.17 & 9.013 & 41.47 & 34.81 \\
\hline 10.44 & 2.854 & 21.36 & 10.12 & 43.86 & 37.91 \\
\hline 11.04 & 3.060 & 22.59 & 11.38 & & \\
\hline \multicolumn{6}{|c|}{ Adiabatic calorimetry } \\
\hline 6.04 & 5.44 & 67.31 & 70.57 & 155.49 & 157.3 \\
\hline 6.84 & 2.83 & 69.09 & 72.80 & 158.98 & 160.1 \\
\hline 7.12 & 3.43 & 70.86 & 74.98 & 162.48 & 162.8 \\
\hline 7.46 & 2.95 & 72.83 & 77.36 & 170.24 & 168.6 \\
\hline 7.95 & 2.85 & 75.09 & 80.03 & 174.24 & 171.5 \\
\hline 8.33 & 2.58 & 77.31 & 82.60 & 177.77 & 174.0 \\
\hline 8.76 & 3.21 & 79.38 & 84.11 & 181.31 & 176.5 \\
\hline 9.68 & 2.86 & 79.52 & 85.12 & 184.83 & 178.8 \\
\hline 10.66 & 3.24 & 81.74 & 87.60 & 188.36 & 181.2 \\
\hline 11.98 & 3.44 & 81.88 & 88.10 & 191.90 & 183.4 \\
\hline 13.04 & 4.22 & 83.98 & 90.06 & 195.53 & 185.7 \\
\hline 14.25 & 4.65 & 84.21 & 88.89 & 199.11 & 187.9 \\
\hline 15.43 & 5.42 & 86.25 & 92.53 & 203.09 & 190.2 \\
\hline 16.73 & 5.82 & 86.41 & 92.40 & 207.48 & 192.8 \\
\hline 18.01 & 6.45 & 88.61 & 94.78 & 211.96 & 195.3 \\
\hline 19.29 & 8.04 & 88.64 & 95.07 & 216.39 & 197.7 \\
\hline 20.75 & 9.60 & 90.82 & 97.95 & 220.76 & 199.9 \\
\hline 23.52 & 11.52 & 93.05 & 99.68 & 225.14 & 201.9 \\
\hline 25.69 & 14.00 & 94.91 & 101.6 & 229.51 & 204.0 \\
\hline 27.81 & 16.58 & 95.36 & 102.4 & 234.05 & 206.1 \\
\hline 29.79 & 19.10 & 97.60 & 105.1 & 238.47 & 208.2 \\
\hline 31.75 & 21.67 & 97.65 & 104.4 & 242.89 & 210.2 \\
\hline 33.72 & 24.37 & 99.86 & 106.6 & 247.23 & 212.2 \\
\hline 35.66 & 26.79 & 100.06 & 106.8 & 251.58 & 214.0 \\
\hline 37.53 & 29.62 & 103.06 & 109.9 & 255.87 & 215.7 \\
\hline 39.38 & 32.38 & 106.69 & 113.4 & 260.16 & 217.4 \\
\hline 41.21 & 35.06 & 107.19 & 113.9 & 264.42 & 219.0 \\
\hline 43.04 & 37.45 & 110.29 & 117.0 & 268.67 & 220.5 \\
\hline 44.86 & 39.85 & 111.18 & 117.8 & 272.87 & 222.0 \\
\hline
\end{tabular}


Table 1. (Contd.)

\begin{tabular}{|c|c|c|c|c|c|}
\hline$T, \mathrm{~K}$ & $C_{p}, \mathrm{~J} \mathrm{~mol}^{-1} \mathrm{~K}^{-1}$ & $T, \mathrm{~K}$ & $C_{p}, \mathrm{~J} \mathrm{~mol}^{-1} \mathrm{~K}^{-1}$ & $T, \mathrm{~K}$ & $C_{p}, \mathrm{~J} \mathrm{~mol}^{-1} \mathrm{~K}^{-1}$ \\
\hline 46.66 & 42.57 & 113.90 & 120.4 & 277.04 & 223.4 \\
\hline 48.46 & 45.24 & 114.71 & 121.2 & 281.21 & 224.7 \\
\hline 50.26 & 47.51 & 117.50 & 123.9 & 285.30 & 226.0 \\
\hline 52.05 & 50.02 & 118.19 & 124.5 & 289.38 & 227.3 \\
\hline 53.95 & 52.58 & 121.68 & 127.8 & 293.45 & 228.5 \\
\hline 56.26 & 55.82 & 129.22 & 134.8 & 297.48 & 229.7 \\
\hline 58.31 & 58.68 & 133.23 & 138.4 & 301.39 & 230.8 \\
\hline 60.14 & 61.18 & 136.77 & 141.5 & 305.84 & 232.0 \\
\hline 61.99 & 63.67 & 144.50 & 148.2 & 312.25 & 234.4 \\
\hline 63.75 & 65.99 & 148.51 & 151.6 & 319.75 & 236.4 \\
\hline 65.54 & 68.31 & 151.99 & 154.5 & 327.08 & 239.1 \\
\hline
\end{tabular}

Table 2. Coefficients of Eqs. (1) and (2) approximating the temperature dependence of the molar heat capacity of terbium hafnate at $6-330 \mathrm{~K}$ and $p=101.3 \mathrm{kPa}$

\begin{tabular}{c|c}
\hline \multicolumn{2}{c}{$C_{p}=\Sigma a_{i} \ln (T / 400)^{i}(6-15 \mathrm{~K})$} \\
\hline$i$ & $a_{i}$ \\
\hline 0 & 355.2435 \\
1 & 261.9488 \\
2 & 64.91673 \\
3 & 5.368378 \\
\hline$C_{p}=3 R \Sigma a_{i}\left(\left(\theta_{i} / T\right)^{2}\right) e^{\theta i / T} /\left(e^{\theta i / T}-1\right)^{2}(15-330 \mathrm{~K})$ \\
\hline$a_{i}$ & $\theta_{i}$ \\
\hline 0.12153 & 7.2915 \\
1.4780 & 103.628 \\
4.0437 & 246.615 \\
5.7318 & 671.243 \\
\hline
\end{tabular}

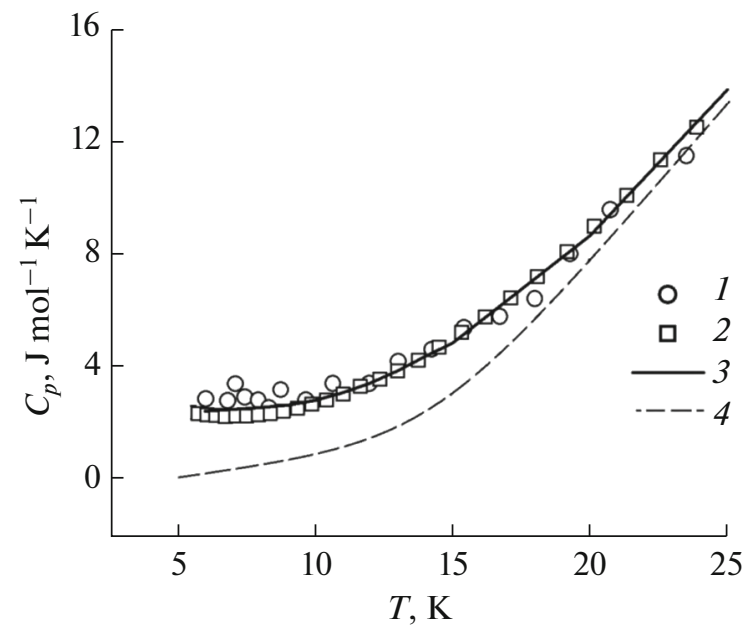

Fig. 3. Experimental dependences of the molar heat capacity of terbium hafnate (pyrochlore) in the range 6-25 K: (1) adiabatic calorimetry data, (2) relaxation calorimetry data, and (3) smoothing curve (Eqs. (1) and (2)), and (4) molar heat capacity of lanthanum hafnate (pyrochlore) [19]. because the lattice heat capacity of terbium hafnate should be close to the lattice heat capacity of lanthanum hafnate since the difference in molar weight between these substances does not exceed $\sim 5 \%$. The contribution of the low-temperature magnetic component of the molar heat capacity to the increment in the enthalpy at $298 \mathrm{~K}$ is typically within the measurement error, whereas the entropy can reach $\Delta S=2 R \ln 2 \approx$ $11.5 \mathrm{~J} \mathrm{~mol}^{-1} \mathrm{~K}^{-1}[20,21]$. However, more accurate determination of the entropy of the magnetic transformation requires additional experiments at very low temperatures. Being unable to measure the molar heat capacity below $6 \mathrm{~K}$, we calculated the thermodynamic functions of terbium hafnate from smoothed values of the molar heat capacity in the range $6-330 \mathrm{~K}$ without talking into account the contributions of the values of the functions in the range $0-6 \mathrm{~K}$ (Table 3).

Along with the magnetic transformations at very low temperatures, the interaction of $4 f$ electrons with the crystal field leads to an increase in the molar heat capacity of compounds of lanthanides (except compounds of $\mathrm{La}$ and $\mathrm{Lu}$ ) [20-23]. The general form of the excess molar heat capacity can be found by subtracting the lattice heat capacity of terbium hafnate, which, as noted above, differs insignificantly from the molar heat capacity of lanthanum hafnate. Anand et al. [12] performed such a calculation, taking into account that the molar weight of terbium hafnate is larger than that of lanthanum hafnate. However, in our opinion, the upward correction of the lattice heat capacity in weight is not fully justified because the molar heat capacity is dominated by the lanthanide contraction, which acts in the opposite direction, i.e., decreases molar heat capacity [22, 23]. Figure 4 presents the difference

$$
\begin{gathered}
\Delta C_{p}\left(\mathrm{~J} \mathrm{~mol}^{-1} \mathrm{~K}^{-1}\right) \\
=C_{p}\left(\mathrm{~Tb}_{2} \mathrm{Hf}_{2} \mathrm{O}_{7}\right)-C_{p}\left(\mathrm{La}_{2} \mathrm{Hf}_{2} \mathrm{O}_{7}\right),
\end{gathered}
$$


Table 3. Thermodynamic functions of terbium hafnate (pyrochlore) at $6-330 \mathrm{~K}$ and $p=101.3 \mathrm{kPa}$

\begin{tabular}{|c|c|c|c|c|}
\hline$T, \mathrm{~K}$ & $C_{p}^{\circ}, \mathrm{J} \mathrm{mol}^{-1} \mathrm{~K}^{-1}$ & $\begin{array}{c}S^{\circ}(T)-S^{\circ}(6 \mathrm{~K}), \\
\mathrm{J} \mathrm{mol}^{-1} \mathrm{~K}^{-1}\end{array}$ & $\begin{array}{c}H^{\circ}(T)-H^{\circ}(6 \mathrm{~K}) \\
\mathrm{J} \mathrm{mol}^{-1}\end{array}$ & $\begin{array}{c}\Phi^{\circ}(T)-\Phi^{\circ}(6 \mathrm{~K}) \\
\mathrm{mol}^{-1} \mathrm{~K}^{-1}\end{array}$ \\
\hline 6 & 2.457 & 0 & 0 & 0 \\
\hline 7 & 2.527 & 0.3853 & 2.492 & 0.0847 \\
\hline 8 & 2.573 & 0.7266 & 5.043 & 0.193 \\
\hline 9 & 2.669 & 1.036 & 7.663 & 0.314 \\
\hline 10 & 2.842 & 1.326 & 10.42 & 0.439 \\
\hline 11 & 3.103 & 1.609 & 13.39 & 0.568 \\
\hline 12 & 3.452 & 1.894 & 16.67 & 0.699 \\
\hline 13 & 3.886 & 2.187 & 20.34 & 0.832 \\
\hline 14 & 4.398 & 2.494 & 24.48 & 0.967 \\
\hline 15 & 4.733 & 2.801 & 28.93 & 0.977 \\
\hline 20 & 8.687 & 4.661 & 61.73 & 1.272 \\
\hline 25 & 13.87 & 7.142 & 117.8 & 1.882 \\
\hline 30 & 19.67 & 10.18 & 201.4 & 2.750 \\
\hline 35 & 25.99 & 13.68 & 315.4 & 3.838 \\
\hline 40 & 32.78 & 17.58 & 462.1 & 5.117 \\
\hline 45 & 39.88 & 21.85 & 643.6 & 6.567 \\
\hline 50 & 47.07 & 26.43 & 861.0 & 8.169 \\
\hline 60 & 61.06 & 36.26 & 1402 & 11.77 \\
\hline 70 & 73.92 & 46.65 & 2078 & 15.78 \\
\hline 80 & 85.64 & 57.30 & 2877 & 20.12 \\
\hline 90 & 96.49 & 68.02 & 3788 & 24.67 \\
\hline 100 & 106.8 & 78.72 & 4805 & 29.39 \\
\hline 110 & 116.6 & 89.36 & 5922 & 34.22 \\
\hline 120 & 126.2 & 99.92 & 7136 & 39.13 \\
\hline 130 & 135.4 & 110.4 & 8444 & 44.09 \\
\hline 140 & 144.2 & 120.7 & 9843 & 49.09 \\
\hline 150 & 152.7 & 131.0 & 11330 & 54.11 \\
\hline 160 & 160.7 & 141.1 & 12890 & 59.13 \\
\hline 170 & 168.3 & 151.1 & 14540 & 64.16 \\
\hline 180 & 175.4 & 160.9 & 16260 & 69.18 \\
\hline 190 & 182.1 & 170.6 & 18050 & 74.18 \\
\hline 200 & 188.3 & 180.1 & 19900 & 79.16 \\
\hline 210 & 194.0 & 189.4 & 21810 & 84.11 \\
\hline 220 & 199.4 & 198.5 & 23780 & 89.04 \\
\hline 230 & 204.4 & 207.5 & 25800 & 93.93 \\
\hline 240 & 209.0 & 216.3 & 27860 & 98.78 \\
\hline 250 & 213.3 & 224.9 & 29980 & 103.6 \\
\hline 260 & 217.3 & 233.4 & 32130 & 108.4 \\
\hline 270 & 221.0 & 241.6 & 34320 & 113.1 \\
\hline 280 & 224.4 & 249.7 & 36550 & 117.8 \\
\hline 290 & 227.6 & 257.7 & 38810 & 122.4 \\
\hline 298.15 & $230.0 \pm 1.2$ & $264.0 \pm 3.0$ & $40670 \pm 220$ & $126.1 \pm 1.5$ \\
\hline 300 & 230.5 & 265.4 & 41100 & 127.0 \\
\hline 310 & 233.3 & 273.0 & 43420 & 131.5 \\
\hline 320 & 235.8 & 280.5 & 45760 & 136.0 \\
\hline 330 & 238.2 & 287.8 & 48134 & 140.5 \\
\hline 340 & 240.4 & 294.9 & 50527 & 144.9 \\
\hline
\end{tabular}




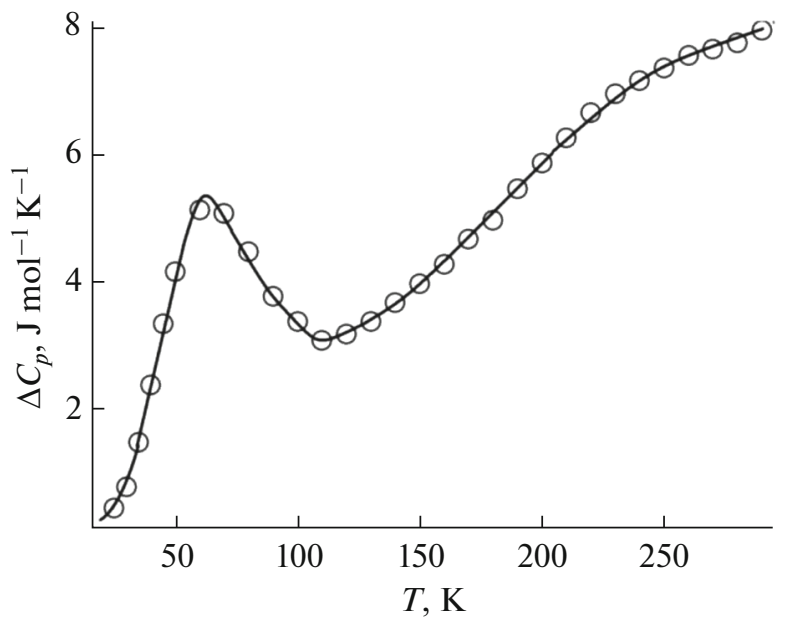

Fig. 4. Difference of the molar heat capacities of terbium and lanthanum hafnates.

which gives an idea of the general form of the temperature dependence of the Schottky anomaly for $\mathrm{Tb}_{2} \mathrm{Hf}_{2} \mathrm{O}_{7}$ (pyrochlore). The anomaly has a maximum at $\sim 55 \mathrm{~K}$ and minimum of $\sim 125 \mathrm{~K}$, which filly coincides with the experimental and calculated values of the Schottky anomaly presented in graphical form [12].

\section{CONCLUSIONS}

In this work, the molar heat capacity of terbium hafnate of the pyrochlore structural type was measured, and the thermodynamic functions were calculated in the temperature range $6-330 \mathrm{~K}$ using the smoothed values of the molar heat capacity. The standard thermodynamic parameters at $298.15 \mathrm{~K}$ are the following: $C_{p}^{\circ}=230.0 \pm 1.2 \mathrm{~J} \mathrm{~mol}^{-1} \mathrm{~K}^{-1}, S^{\circ}(T)-S^{\circ}(6 \mathrm{~K})=$ $264.0 \pm 3.0 \mathrm{~J} \mathrm{~mol}^{-1} \mathrm{~K}^{-1}, H^{\circ}(T)-H^{\circ}(6 \mathrm{~K})=40670 \pm$ $220 \mathrm{~J} \mathrm{~mol}^{-1}$, and $\Phi^{\circ}(T)-\Phi^{\circ}(6 \mathrm{~K})=126.1 \pm 1.5 \mathrm{~J} \mathrm{~mol}^{-1}$ $\mathrm{K}^{-1}$. The general form of the Schottky anomaly was determined.

\section{ACKNOWLEDGMENTS}

This work was performed using equipment of the Center for Common Use of Physical Methods of Investigation of Substances and Materials, Kurnakov Institute of General and Inorganic Chemistry, Russian Academy of Sciences, Moscow, Russia.

Authors acknowledge PhD A.A. Ashmarin for assistance in X-ray studies.

\section{FUNDING}

This work was supported by the Russian Science Foundation (project no. 18-13-00025, https://rscf.ru/project/18-13-00025/).

\section{CONFLICT OF INTEREST}

The authors declare that they have no known competing financial interests or personal relationships that could have appeared to influence the work reported in this paper.

\section{OPEN ACCESS}

This article is licensed under a Creative Commons Attribution 4.0 International License, which permits use, sharing, adaptation, distribution and reproduction in any medium or format, as long as you give appropriate credit to the original author(s) and the source, provide a link to the Creative Commons licence, and indicate if changes were made. The images or other third party material in this article are included in the article's Creative Commons licence, unless indicated otherwise in a credit line to the material. If material is not included in the article's Creative Commons licence and your intended use is not permitted by statutory regulation or exceeds the permitted use, you will need to obtain permission directly from the copyright holder. To view a copy of this licence, visit http://creativecommons.org/licenses/by/4.0/.

\section{REFERENCES}

1. E. R. Andrievskaya, J. Eur. Ceram. Soc. 28, 2363 (2008).

https://doi.org/10.1016/jeurceramsoc.2008.01.009

2. P. A. Arsen'ev, V. B. Glushkova, A. A. Evdokimov, et al., Rare-Earth Element Compounds: Zirconates, Hafnates, Niobates, Tantalates, and Antimonates (Nauka, Moscow, 1985) [in Russian].

3. M. J. D. Rushton, R. W. Grimes, C. R. Stanek, et al., J. Mater. Res. 19, 1603 (2004). https://doi.org/10.1557/JMR.2004.0231

4. M. A. Subramanian, G. Aravamudan, and G. V. Subba Rao, Prog. Solid State Chem. 15, 55 (1983). https://doi.org/10.1016/0079-6786(83)90001-8 
5. V. A. Kabanova, V. V. Popov, Ya. V. Zubavichus, et al., J. Phys.: Conf. Ser. 712, 012113 (2016). https://doi.org/10.1088/1742-6596/712/1/012113

6. A. V. Shlyakhtina, M. V. Boguslavsky, S. Yu. Stefanovich, et al., Inorg. Mater. 42, 519 (2006). https://doi.org/10.1134/S002016850605013X

7. Y. L. Aung, A. Ikesue, R. Yasuhara, and Y. Iwamoto, J. Alloys Compd. 822, 153564 (2020). https://doi.org/10.1016/j.jallcom.2019.153564

8. R. Yasuhara and A. Ikesue, Opt. Express 27, 7485 (2019). https://doi.org/10.1364/OE.27.007485

9. V. V. Popov, A. P. Menushenkov, A. A. Yaroslavtsev, et al., J. Alloys Compd. 689, 669 (2016). https://doi.org/101016/j.jallcom.2016.08.019

10. V. V. Popov, Ya. V. Zubavichus, A. P. Menushenkov, et al., Russ. J. Inorg. Chem. 60, 16 (2015). https://doi.org/10.1134/S003602361501009X

11. A. P. Menushenkov, V. V. Popov, Ya. V. Zubavichus, and A. A. Yaroslavtsev, J. Struct. Chem. 57, 1450 (2016). https://doi.org/10.1134/s0022476616070210

12. V. K. Anand, L. Opherden, J. Xu, et al., Phys. Rev. B 97, 094402 (2008). https://doi.org/10.1103/physrevb.97.094402

13. M. A. Ryumin, G. E. Nikiforova, A. V. Tyurin, et al., Inorg. Mater. 56, 97 (2020). https://doi.org/10.1134/S0020168520010148

14. V. N. Guskov, A. V. Tyurin, A. V. Guskov, et al., Ceram. Int. 46, $12822(2020)$.

https://doi.org/10.1016/j.ceramint.2020.02.052
15. P. G. Gagarin, A. V. Guskov, V. N. Guskov, et al., Ceram. Int. 47, 2892 (2021). https://doi.org/10.1016/j.ceramint.2020.09072

16. P. E. R. Blanchard, S. Lio, B. J. Kennedy, et al., J. Phys. Chem. C 117, 2266 (2013). https://doi.org/10.1021/jp311329q

17. M. E. Wieser, Pure Appl. Chem. 78, 2051 (2006). https://doi.org/10.1351/pac200678112051

18. A. L. Voskov, I. B. Kutsenok, and G. F. Voronin, CALPHAD: Comput. Coupling Phase Diagrams Thermochem. 61, 50 (2018). https://doi.org/10.1016/j.calphad.2018.02.001

19. V. N. Guskov, P. G. Gagarin, A. V. Guskov, et al., Russ. J. Inorg. Chem. 64, 1436 (2019). https://doi.org/10.1134/S0036023619110068

20. H. W. J. Blöte, R. F. Wielinga, and W. J. Huiskamp, Phys. A 43, 549 (1969). https://doi.org/10.1016/0031-8914(69)90187-6

21. J. Xu, V. K. Anand, A. K. Bera, et al., Phys. Rev. B 92 , 224430 (2015). https://doi.org/10.1103/PhysRevB.92.224430

22. R. D. Chirico and E. F. Westrum, Jr., J. Chem. Thermodyn. 12, 71 (1980). https://doi.org/10.1016/0021-9614(80)90118-4

23. R. D. Chirico and E. F. Westrum, Jr., J. Chem. Thermodyn. 12, 311 (1980).

https://doi.org/10.1016/0021-9614(80)90143-3

Translated by V. Glyanchenko 